\title{
PEDAGOGICAL PRAXIS IN ARCHITECTURE DESIGN STUDIO: (CASE STUDY APPLIED ON SOPHOMORE ARCHITECTURE STUDENT)
}

\begin{abstract}
EMAD H. RABBOH
Canadian international college (CIC)- Egypt.

ABSTRACT

Optimum architectural pedagogy, the best possible way to implement curricula at the undergraduate level, necessitates in-depth research into a vast array of academic, technical and psychological considerations, in order to ascertain the best teaching approach. This study has included the results of student feedback surveys to assist in the preliminary design phase of this study aimed at divining best teaching methodologies. In addition, the design of the Praxis also took into consideration the findings of published literature in this field of research. Both of these data sources were then combined into a methodology, which was applied to an undergraduate class at the Canadian International College, El Sheikh Zayed Campus, Giza, Cairo (CIC) for students enrolled in architectural design 2, during the fall 2015, spring 2016 and fall 2016. Subsequently, through the survey again, student input was again sought, reactions to those aspects that had been implemented by the end of the semester. A questionnaire was designed and distributed to appraise the overall experiment in practice design in the design studio. The most important aspect proved to be the introductory session phase for the students, which occurred at the initiation phase of the project. The information gathered was then used by the faculty to review the proposed pedagogical approach, adjust teaching plans, and applies the improvements to the upcoming design studios.
\end{abstract}

Keywords: Architecture design studio-Architecture pedagogy- Critique criteria-Design studio jurypsychological aspects in design studio.

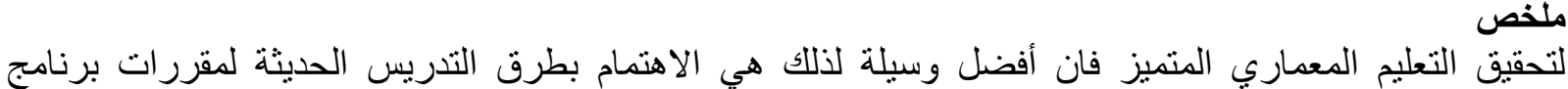
الهندسة المعمارية، ويتطلب ذللك إجر اء بحوث متعمقة في مجموعة واسعة من الاعتئي الاعتبار ات الأكاديمية و الفنية و النفسية

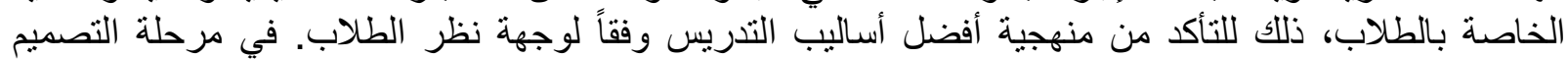

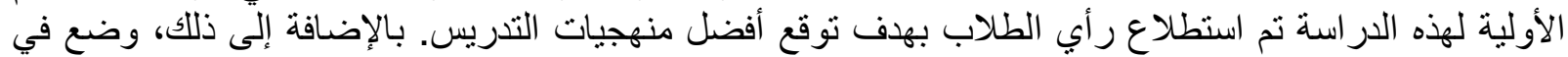

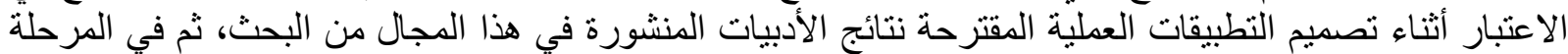

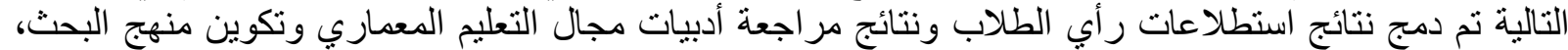

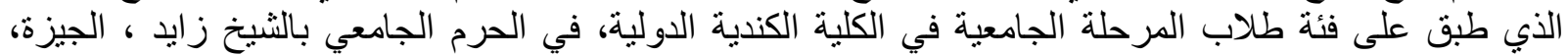

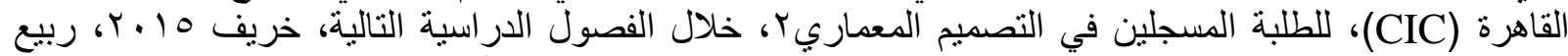

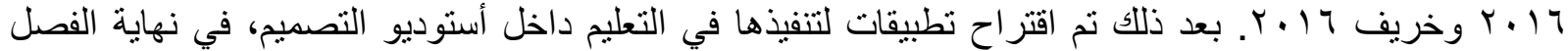

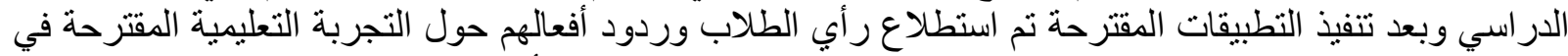

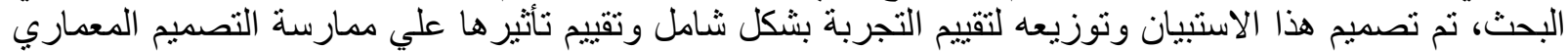

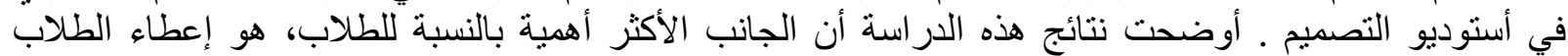

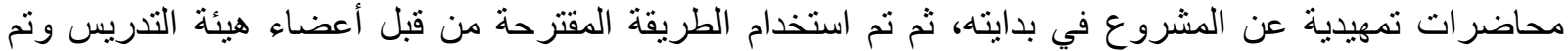

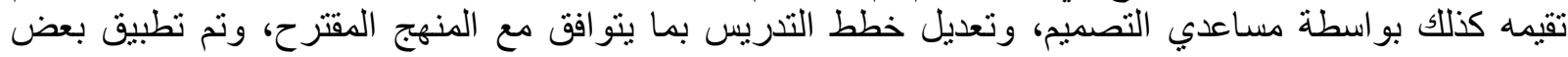
التطوير في التجربة المقترحة في استوديوهات التصني التصميم القادمة. 


\section{INTRODUCTION:}

Recent developments that have emerged through the advancement in the field of education in general and architectural education in particular, must be reflected in the architectural pedagogy of today. The emergence of the specialized science, which focuses on the human mind and how this impact the acquirement of knowledge, especially in scientific fields must be taken into consideration. Add to this the intricacy of technological innovations, which engenders a direct evolution of not only the humanities and psychological sciences, but by corollary, upon architectural pedagogy. The architectural design studio should evolve dramatically in order to keep pace with recent trends in undergraduate education. In addition to understanding the mentality of the students in this age group, what also must be incorporated is consideration for the different learning styles they have, in order to deliver knowledge and architectural information in such a way that it is appropriate for each individual's learning style. Perhaps more importantly, it is necessary to understand the psychological facets of students, and how to generate internal motivation that leads to the growth of architectural concepts for students, moreover, inspires them to create and propagate innovative architectural concepts. All this, while maintaining an aesthetically pleasing and thought-provoking milieu in the design studio. Without a doubt, the development of the scientific level of architectural students contributes to the progression of the architectural profession, which in turn, affects the community and contributes to the development of that community, which may, lessen social problems through the creation of environments, that is not only architecturally and artistically appealing, but offer some resolution to social and environmental problems.

\subsection{Literature review: The previous studies can be classified into four groups as follows:}

Learning styles in architectural pedagogy. These studies examined the various learning styles in architectural pedagogy', referencing Kolb's model ${ }^{\top}$.

Critiques technique in the design studio. This research attempts to propose models to evaluate critiques styles. Knowledge of design is communicated to the student through the critiques in the design studio . A design collaboration model was developed to propose a medium for the on-line collaboration of the design courses ${ }^{\xi}$. Yet another study offers a detailed qualitative and quantitative representation of the critiques via analysis of three case studies .

Learning tools and trends in the design studio. This research illustrates modern trends and tools in design, for example, the digital design studio ${ }^{-}$. Some models are proposed to encompass learning strategies ${ }^{1}-{ }^{\prime}$. Other research implements comparative studies for design studios ${ }^{19}$, and a few studies monitor transformations in the design studio, .'. Still others discuss how to improve creativity in design education ${ }^{r}$. Lastly, there is a proposed methodology to evolve parametric thinking within undergraduate design studios ${ }^{\top T}$.

Learning outcomes from design studio. The general intent of these studies is to design student learning outcomes in undergraduate architectural education and assessments ${ }^{r \varepsilon}$, as well as discussing the results of the students learning assessments. ${ }^{\mathrm{O}-\mathrm{Y} Y}$.

\subsection{Methodology:}

The present study aims to develop architectural education and enhance the learning/teaching experience of both the faculty and students in the architectural design studio, as well as enhancing mutual trust between them. The implementation of the study objectives was conducted via field study applied to architecture level 2 students (38 students) at CIC during fall 2015 and spring 2016 academic years. The field study commenced with an initial survey with the assigned students to study in architectural design 2 (sophomore level-early level architecture design studio). Surveying also included teachers' assistants, in order to identify the status quo and benefit from their prior experience with regard to the problems they had encountered, and what the goals they looked forward to achieving. Subsequent to the above, the study framework as well as expected outcomes were revised and adjusted to include this data information. A questionnaire in Appendix (A) was circulated among students and teaching assistants to ascertain the extent that the proposed methodology might benefit them. This questionnaire included the aspects that have been applied. Following this, the students completed the questionnaires choosing from a scale 
ranging from an extremely positive to an extremely negative response. The ultimate goal was the development of an improved architectural pedagogy for upcoming years via a fruitful open discussion between faculty members and students.

\section{FIELD STUDY (DESIGN STUDIO PEDAGOGICAL PRAXIS ASPECTS):}

Following individual interviews and group discussions, thirteen aspects were elected as foci for the design studio Praxis as delineated in figure (1) and its goal of improved architectural pedagogy with student focus. These aspects were further grouped into three major categories as follows:

\subsection{Psychological and human aspects:}

Psychoanalytical aspects were taken into account to provide for optimum architectural pedagogy and in achieving the goal of a comfortable and non-threatening learning environment for students. It is certainly a contributory factor to effecting high student achievement. Consideration for and inclusion of psychological aspects was incorporated in the Praxis through the following: 3.1.1 Diminish stresses at the initial phase of the project. This was strongly recommended in the initial stages of the project to simplify the project aspects. . The proposed strategy is to not assign students grades in the project Critiques relying on the findings of direct observations of previous projects, which is that during the previous design (design 1) did not formulate to them introductory lectures concerning the project. Here there would be decidedly a lack of sufficient architectural information at this stage of architectural education design. Similarly, the faculty requests for esquisse from the students in the second week, simply to explore the general level of students. Obviously, the students need considerable architectural information and guidance as well as lectures to understand the projects. For all the previously cited reasons, in the initial phases of the projects, assessment is limited to critiques of student work and ideas without assigning grades.

3.1.2 Take into account individual differences among students. To effect this, an explorative step had been done via appraisal of the level of each student individually to determine the pros and cons of each student, taking into account individual differences among the students, with a view to developing their skills on an individual basis. More importantly, student deliverables assessment should be based on an individual student's base level at the initial stage and its progression through subsequent stages of the project. If the low-level students were evaluated in comparison with the high-level students only, this would lead to discouragement, frustration and a gradual decline in their levels of achievement. Notably, few of the enrolled students have decided to leave architecture major completely, after dealing with them not only comparing them with high-level students but also based on themselves the prior level. 


\begin{tabular}{|rl|}
\hline B & Diminish stresses at the initial phase of the project. \\
\hline B & Take into consideration individual differences among students. \\
\hline B & Build an environment of mutual trust between the faculty and students. \\
\hline B & Ensure that the stimuli and motivational strategies were sufficient. \\
\hline B & Assay initial architectural student mindsets with a view to ameliorating misconceptions at the \\
outset. \\
\hline 3.2 Architectural capabilities development aspects. \\
\hline B & Build epistemological freedom and an open-minded milieu in the design studio. \\
\hline B & Counseling in architectural decision- making with the students. \\
\hline B & Expound the integration in architectural design in the onset of the project. \\
\hline B & Introductory sessions for the student at the initiation phase of the project. \\
\hline B & Work on the student idea. \\
\hline 3.3 Design studio management aspects. \\
\hline B & Assessment based on pre-determined criteria. \\
\hline B & Illustrate the design process; the timetable for the initial phase of the project. \\
\hline B & Dividing Students into groups with individual Instructor to boost the follow-up for each student. \\
\hline
\end{tabular}

Figure (1) design studio pedagogical applied aspects.

3.1.3 Build an environment of mutual trust between the faculty and students. It became clear that in the initial stages of the first project there was a low level of confidence among the students and teaching assistants; (some tutors teaches the same student in previous courses). Accordingly, the focus was on building mutual trust between students and faculty through open conversations and meetings with students and teaching assistants. In this context, the faculty held focus group meetings during the design studio, which was to bridge the psychological gap between them. These open discussions included an explanation to the students of the different understandings in the assessment of architectural designs. Furthermore, it included insights by the faculty into architectural design and the appropriate approach to be taken with regard to the assigned project. In numerous situations during the design studio, the author focused on establishing basic principles, For instance, Justice among students, Mutual appreciation among students and teaching assistants. So as to, fulfill an approachable and innovative learning environment in the design studio, where students submit their best after checking that competency-based assessment and there is no prejudice or favoritism to one of the students. Therefore, the assessment criteria are objective criteria and not subjective. In addition to the foregoing, the attainment of a positive environment in the design studio, lead to the faculty satisfaction and enjoy working with students. Besides, it was agreed between everybody on the faculty and students are one team and not a relationship between two detached parties. Necessarily work through team ethos, strongly emphasize on that through various situations during the design process.

3.1.4 Ensure that the stimuli and motivational strategies were sufficient. Motivational strategies and encouragement attempts were included on two levels as follows:

A) The students who had previously been categorized as having a high level/low level of competence, but had at this stage achieved a high score in terms of assessment, were counseled individually and advised that they are still needed to further development of the architectural level of the project and that there was more work that needed to be done.

B) Individual meetings were also held with the students with high level/low level, who had achieved a low score, to endeavor to raise their morale and boost their self-confidence. They were advised of the potentiality of scoring high marks if they improved their architectural level, and were coached in how to develop an action plan to achieve higher grades. The strategies above were utilized to stimulate positive competition among the students, thereby raising the overall level of students. Similarly, the same ongoing motivational strategies were agreed on and implemented by the teaching assistants and were to be used in all phases of the student project, 
regardless of student level. This was to ensure that teaching assistants were not negatively biased towards low-level achieving students, which would then result in the further decline of the level of these students. By necessity, the training of teaching assistants to appreciate all students' efforts, especially the ones who had exerted a lot of effort, regardless of ultimate achievement level. This recognition of effort proved a positive reinforcement through setting scores for this in the assessment criteria in addition to quantity and quality. Examples to follow later in the study. Collaboration among the students was strongly encouraged. Students worked individually on their independent projects, while at the same time assisting their colleagues, inspiring their design ideas, and providing encouragement. This served to further diminish negative competition among students and a possible detrimental effect on the level of the final projects.

3.1.5 Assay initial architectural student mindsets with a view to, ameliorating misconceptions at the outset. Several of the observations in the initial stages of the project seemed to indicate appears a great deal of erroneous architectural concepts that were inconsistent with the basic architectural guidelines, including, for instance, that the project should begin by finalizing the project floor plans. Focus on later elements of the design project, such as the project presentation, which was not vital at this stage, indicated the lack of a logical sequence in the design process phases. The rectification of student mindset relied on the intervention of the instructors regarding this misconception in architecture studio design. Through individual discussions with students during office hours as well as group lectures in the design studio, students were educated as to appropriate sequencing and inclusions at each stage. In terms of psychological aspects of the study, the author viewed it as imperative that all the teaching faculty embrace the attitude that the majority of people can be architects, as long as they providing the appropriate educational ambiance, and take into consideration the psychological aspects of the students. Individual meetings with the students help motivate them. The student performance analysis allows for the assessment of the strengths and weaknesses of each student and informs as to how best to motivate and address any learning deficiencies and discern effective learning strategies for each.

\subsection{Architectural capabilities development aspects.}

In this aspect, the focus is on building architectural character, while at the same time empowering students to self-development, decision-making, configuration and the generation of alternative solutions, as well as the inclusion of self-criticism of ideas and objective thinking. Achieving all of the above is imperative for the development of architectural performance and treatment of design concepts and promotes creative ideas for architecture designers, so that they can build distinctive architectural identity. As well as designing the project, have impressive architectural projects, via the following elucidations in this aspect:

3.2.1 Build epistemological freedom and an open-minded milieu in the design studio._This leads to the formation of an architect with advanced rational and thinking outside the box, and provides for innovative architectural concepts. Furthermore, designing the projects relies on contemporary architectural trends; not only designing projects in accordance with the cognitive styles of course coordinator and design pedagogues. Finally, the assimilation of all of the above leads to the evolutionary stage of creative thinking on the part of the student._As Salama stated: "the concept of creativity in teaching architectural designs is commonly defined under the heading of intuition and talent. As a result, a number of mental skills are left undeveloped." Based on the foregoing, introductory lectures were given concerning the assigned project and presented to the students and the faculty in the preliminary phases of the project, targeting the improvement of creative brainpower, through exemplars of famous architectural projects from the past, as well as including contemporary architectural theories._At a later stage of the project, students were asked to exhibit and illustrate their projects in front of design tutors and their colleagues for open the discussion via a workshop for the development of architectural criticism 
concepts, in order to touring them to develop designs of their own by viewing the different ideas for projects. In addition to this various design, approaches were presented through lectures on contemporary architectural theories in order to evolve diversity among students and the initiation of students to architectural insights.

3.2.2 Counseling in Architectural Decision Making With the Students. Decision-making in the design process requires further application, and trial and error opportunities. Students should conduct a variety of trials to perform conspicuous architectural solutions. In order to teach the students this concept the faculty conducted counseling strategies, presenting the students open concept ideas in order not to influence students into a particular architectural trend. Students should also not be encouraged to mimic the mindset of any faculty member. In order to achieve this, the faculty only assessed the student work and explained the pros and cons of their designs and empowered the students to decide if they need to amend his/her work through all project phases. Moreover, the faculty presented to the students noteable presentation styles and how to develop meaningful architectural concepts.

3.2.3 Explain and expand on integration in architectural design at the outset of the project. Through discussions and observations, it was that, in the mindset of the students, there was a lack of understanding of the fact that architecture is a multidisciplinary discipline that requires integration. To address this issue, several strategies were put into place. For example, students were presented with exemplars that demonstrated how well known architects had integrated various architectural elements in their projects. Moreover, these showed how to fulfill functional and aesthetic characteristics in architectural projects. Furthermore, the author found that the majority of architecture students dealt with various project phases (preliminary research-bubble diagrams-conceptual design-final Avant project) as heterogeneous phases; each phase seemed disconnected from the other phases. For these reasons, the faculty included in their evaluation scores for an integrative solution in the projects' juries.

3.2.4 Introductory sessions for the student at the initiation phase of the project. To prepare students for the project, the faculty initiated architectural sessions in architecture studio: how to commence the project, architectural design guidelines, examples from professional architects as well as those from peers attending other colleges. These sessions served to illustrate the varying professional and student performance levels as well as illustrating modern presentation techniques for their own final project submissions.

3.2.5 Work on student ideas. One of the ground rules used in the design studio, was to respect student ideas, moreover, not to change them in totality or significantly or even to impose the concepts of the faculty member. The explicit task of the faculty was to appraise and analyze student ideas and works. Hence, many brainstorming sessions were held between the students and the faculty, the discussion focusing on the advantages vs. disadvantages of his/her architectural ideas, and leaving the final decision for the student to determine the appropriate or inappropriate architectural ideas for their project. As a further aid, a list of identified lists of major mistakes as well as minor mistakes was provided to assist students in their decisionmaking. Further, the negative implications of each error in various stages of design were included, in order to lessen student design errors.

\subsection{Design studio management aspects.}

Design studio administration requires some sort of project management skills and follow-up on entire design project phases. Similarly, design studio requires elasticity to adapt the project schedule depending upon project circumstances and students' responses to faculty teaching and learning practices and project milestones. Design studio management aspects included were as follows:

3.3.1 Assessment based on pre-determined criteria. When assessment is based on objective standards rather than on positive or negative attitude toward their projects, the students have 
assurance as to the fairness of their grades. If no objective criteria for assessment of projects are used, then the students might believe that the jury are being unduly influenced and/or biased by their preferable architectural trends. Research has proposed various criteria for the assessment of projects, the weight of each element dependent on the specific phase of the project and its intended goals for each stage as shown in Figure (2). There is no doubt that setting objective criteria leads to the satisfaction of the jury in assigning scores and having confidence in their ability to justify such to the students.

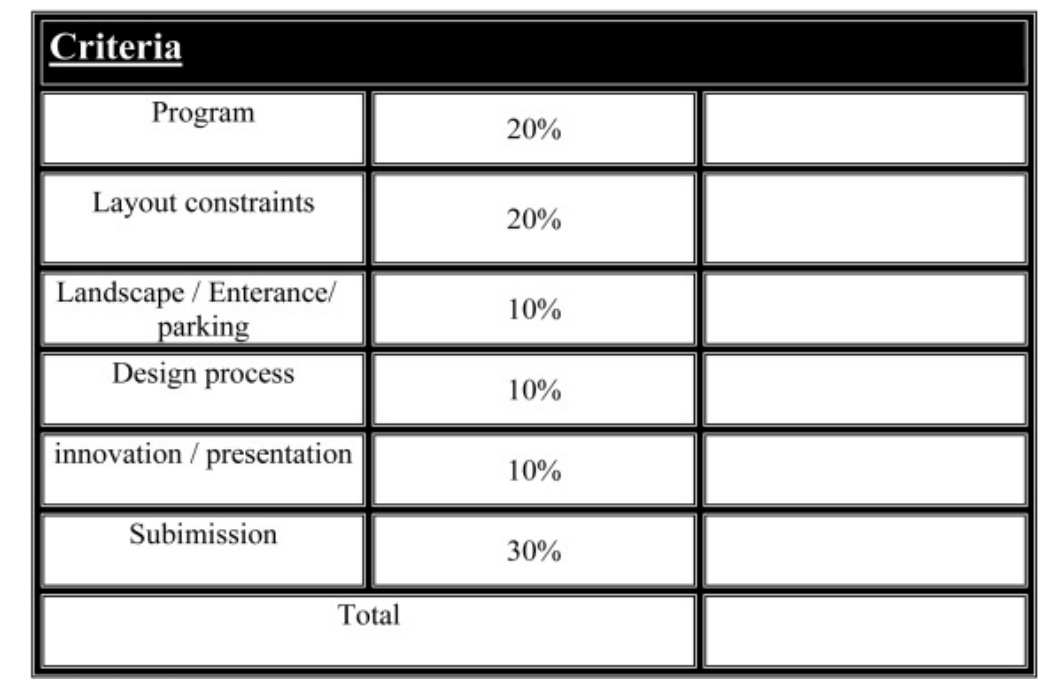

Figure (2) proposed criteria for students' appraisal in the design studio.

3.3.2 Illustrate the design process: the timetable for the initial phase of the project. This leads to an agreement between the faculty of design and students concerning the project milestones and what are the weekly deliverables. Depending on the schedule, students organize their time in order to optimize their efforts to affect the best performance possible within those time parameters. The schedule is used to determine the design process for the various phases and the sequence of the architectural deliverables, as well as required compulsory and elective architectural deliverables.

3.3.3 Divide students into groups with individual instructor to enhance the follow-up for each student. This is one of the remarkably valuable facets of architectural pedagogy, the individual, ongoing follow-up for each student. After observing that, the lack of ongoing individual monitoring of the students by faculty members negatively influenced the architectural level of student projects, a system of tracking individual outcomes was implemented. Students were divided into groups based on their GPA scores on an ascending scale, in order to facilitate some competition among the students and improve the general outcomes for all the diverse student groups. In addition, each group was assigned a faculty supervisor. This had the added effect of creating competition among the teaching assistants who were motivated to implement diverse teaching techniques to raise the outcome levels of their assigned group and attempt to outperform the rest of the groups. In some instances, there were differences of opinion between the students and their assigned supervisor. One resolution was to allow students to assume sole responsibility for their work and choose an alternate faculty member who seemed more attuned to their ideas. Final dispute resolution focused on the necessity to come to some convergence of views and to work as one team. In the second phase of the project, a focus group was conducted in the second project. In this focus group, the students with the same prevalent weaknesses were gathered in one working group. These students needed to further develop some architectural 
skills. The faculty developed a training program to increment the students' capabilities in specific areas where there was deemed to be an insufficiency in architectural level.

\section{RESULTS:}

Certainly, the experiments in architectural pedagogy require ongoing amelioration to accomplish an optimum creative milieu for architectural students. Architectural pedagogy that was addressed in this study was supported through the distribution of a questionnaire to students. It contained the aspects that have been applied in the design studio, and each aspect had five scaled questions. The student expressed his/her opinion towards the implications of the aspects was implemented in the design studio. A summary of the results may be found in Figure (3) with the frequency of each aspect. Firstly, it utilized a qualitative method to assess the aspects using LIKERT scale (extremely positive-positive -....) which the students select from. Secondly, utilizing a quantitative method for other aspects, in order to arrive at the value of each aspect using nonlinear scale for each. Consequently, each value multiplied in its own frequency and adding the values together. Lastly, the final results are tabled in Figure (4). The arithmetic mean of the total applied aspects of this study was calculated as well as statistical measures (Measures of Central Tendency) were used to appraise the overall results of the Praxis.

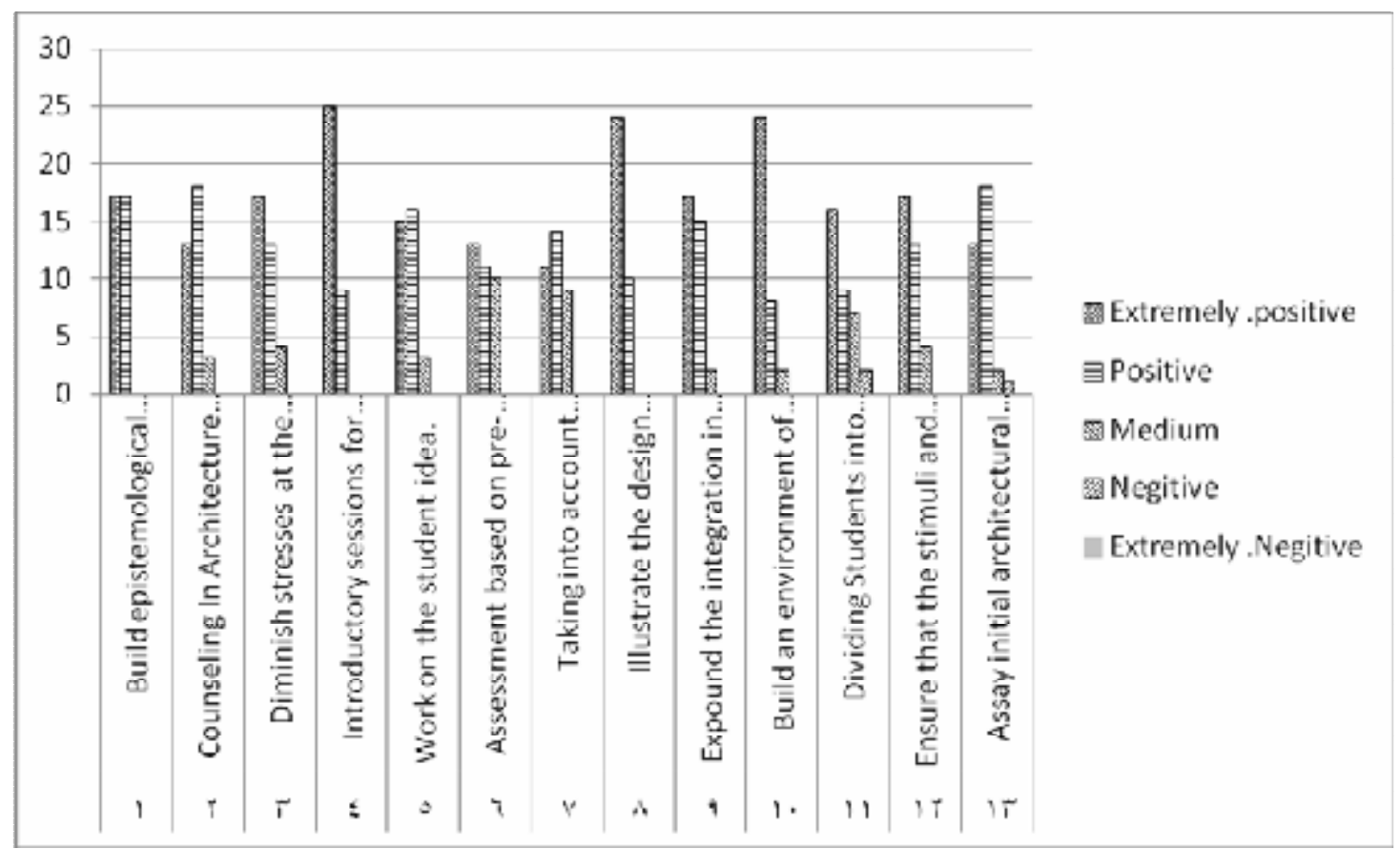

Figure (3) summary of the results for each aspect. 


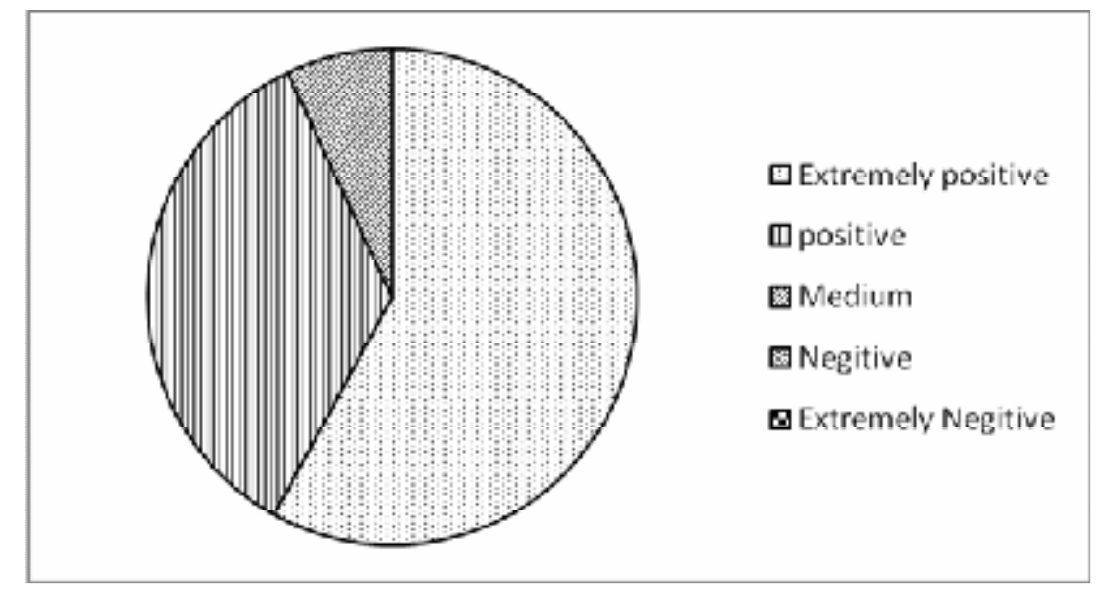

Figure (4) an overall average of the students' opinions toward implications of applied aspects in this study.

\section{DISCUSSION}

Obviously, minor variations among the various aspects emerged, based on the opinion of the students, appeared at the top four aspects their appreciation of the aspects of interest in psychological status at different stages of the project, and relying on it. In one of the projects, the total average grades for the students were not distinct. Nevertheless, the faculty members did not reprove or reproach them. Mistakes, however, were clarified and students were encouraged to raise their resolve and determination to improve the following project.

At the same feedback meeting, which followed the project, the students concurred that the attempts take into account their psyche and understand and show appreciation for their works and projects made a distinct difference in their architectural productivity. They further stressed that, from their point of view, continued encouragement resulted in hard work on the projects in spite of the complications. Some student in prior course (Design I) not presenting their project after facing some psychological stress. However, the same students submit their projects, because of the application of these aspects proposed in this study. With respect to the results questionnaire, (Introductory sessions for the student at the initiation phase of the project) was viewed as most important. This indicates that the students were in dire need of introductory lectures and preliminary guidelines for new projects. It is definite that this guidance reduced their dread of projects and supported them psychologically by methodizing the project progressively, and provided them with further time for research into deeper aspects of the project. In second place was: (Illustrate the design process; the timetable for the initial phase of the project). This reflects the students' interest in the design studio management procedures, the structuring of which guided them to perform well in their projects. Thirdly was (Build mutual trust ambience between the faculty and students). Obviously, this demonstrates the need of students to have a counselor, a motivator who encourages them to achieve at higher levels, at the same time increasing their self-confidence and sympathizing with them. They needed support in times of failure and appreciated the praise in times of achievement and excellence, which, overall, provides a better picture of overall relationship and communication between faculty and students. Fourthly is (Build epistemological freedom and an open-minded environment in the design studio). This reflects the tendency of students to desire freedom of expression in architecture, while working in a design studio, as well as an appreciation of their architectural concepts via design studio critiques as well as the final jury process. Fifthly is (Expound the integration in architectural design in the onset of the project) and to illustrate the feedback process in the design process at all stages. In addition, during discussions, explain to the students that the design process is very much not a strictly sequential or unidirectional process. They stressed that 
they benefit from this aspect and its impact was extremely positive on their designs. Sixth, (Diminish stresses at the initial phase of the project). It is acknowledged that, there were three constraints on any project: time, quality, and cost. Relative to the student's level in the prime phases of the project, time was restricted and the emphasis was on quality. However, left time and cost factors in this phase. It was decided to not award grades in the initial phase of the project, so as, to focus on the extraction of prolific architectural ideas and creative concepts in projects. Seventh, (The stimulus and inducement strategies were sufficient) for them in general. Students were encouraged to complete their projects and present them in quite splendid and impressive professional presentations. The rest of the less notable aspects are denoted successively in the Figure (5).

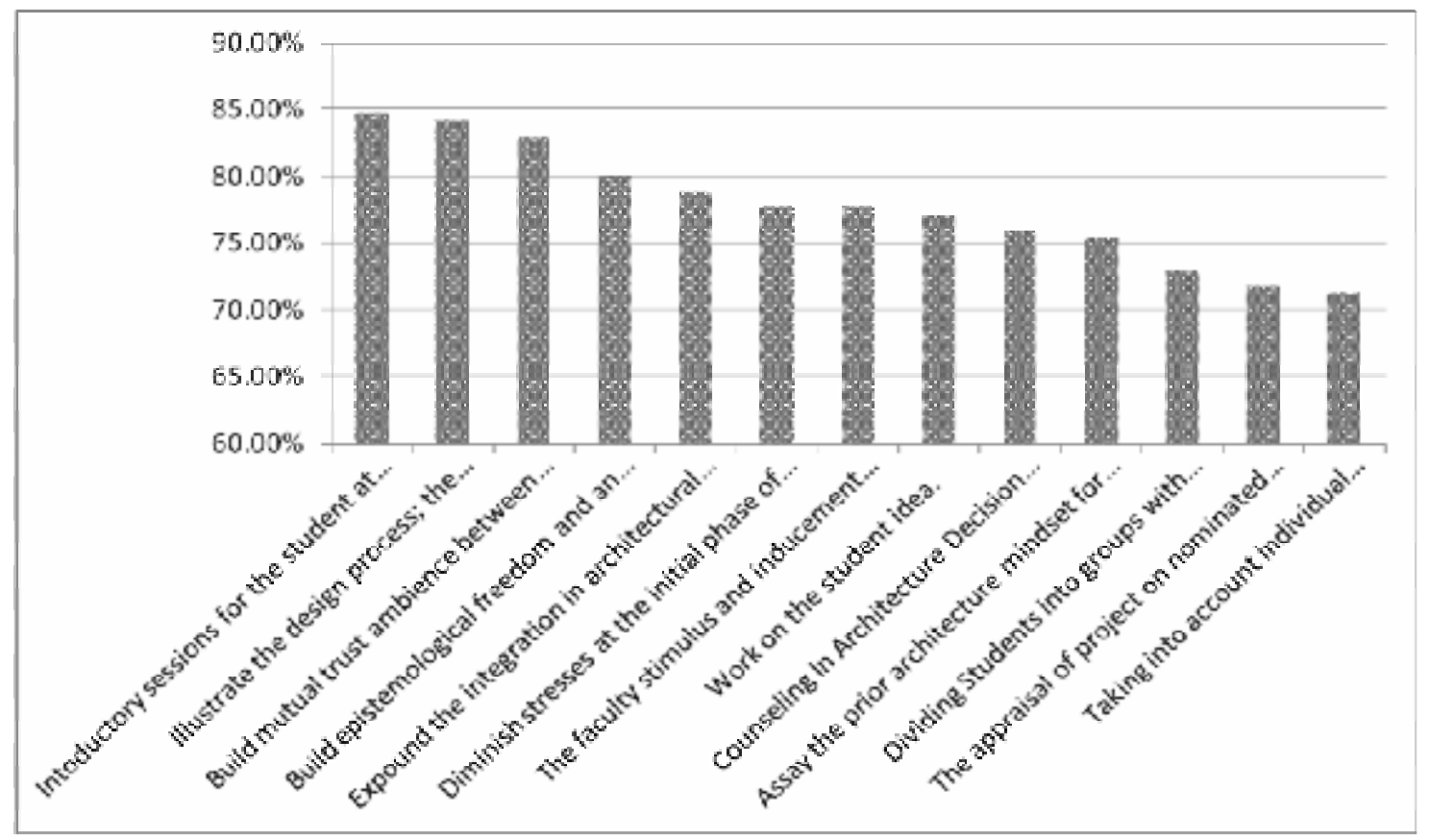

Figure (5) ranking of weighted proposed aspects according to the students' opinions.

Eventually, the students similarly noted the enormous benefit of the appraisal criteria, since it was the reason and motivation for the development of their level in the successive phases of projects.

\section{CONCLUSIONS:}

B Through a direct interview with the candidate student to study Design 2, as well direct observation of the previous project the study extracted design studio pedagogical aspects.

B The aspects above were applied to architectural students in two semesters.

B The study verified the implemented pedagogical aspects via filling out a questionnaire in Appendix (A) by students.

B Ranking for the aspects carried out in this study, depending upon the students' opinions.

B The most important aspect as follows:

1. Introductory sessions for the student at the initiation phase of the project.

2. Illustrate the design process; the timetable for the initial phase of the project.

3. Build an environment of mutual trust between the faculty and students.

4. Build epistemological freedom and an open-minded environment in the design studio. 
5. Expound the integration in architectural design in the onset of the project.

6. Diminish stresses at the initial phase of the project.

7. The stimulus and inducement strategies were sufficient.

B The faculty amended the proposed aspects and update it

ß In Figure (6) samples of students' projects after implementing the proposed architecture pedagogy.

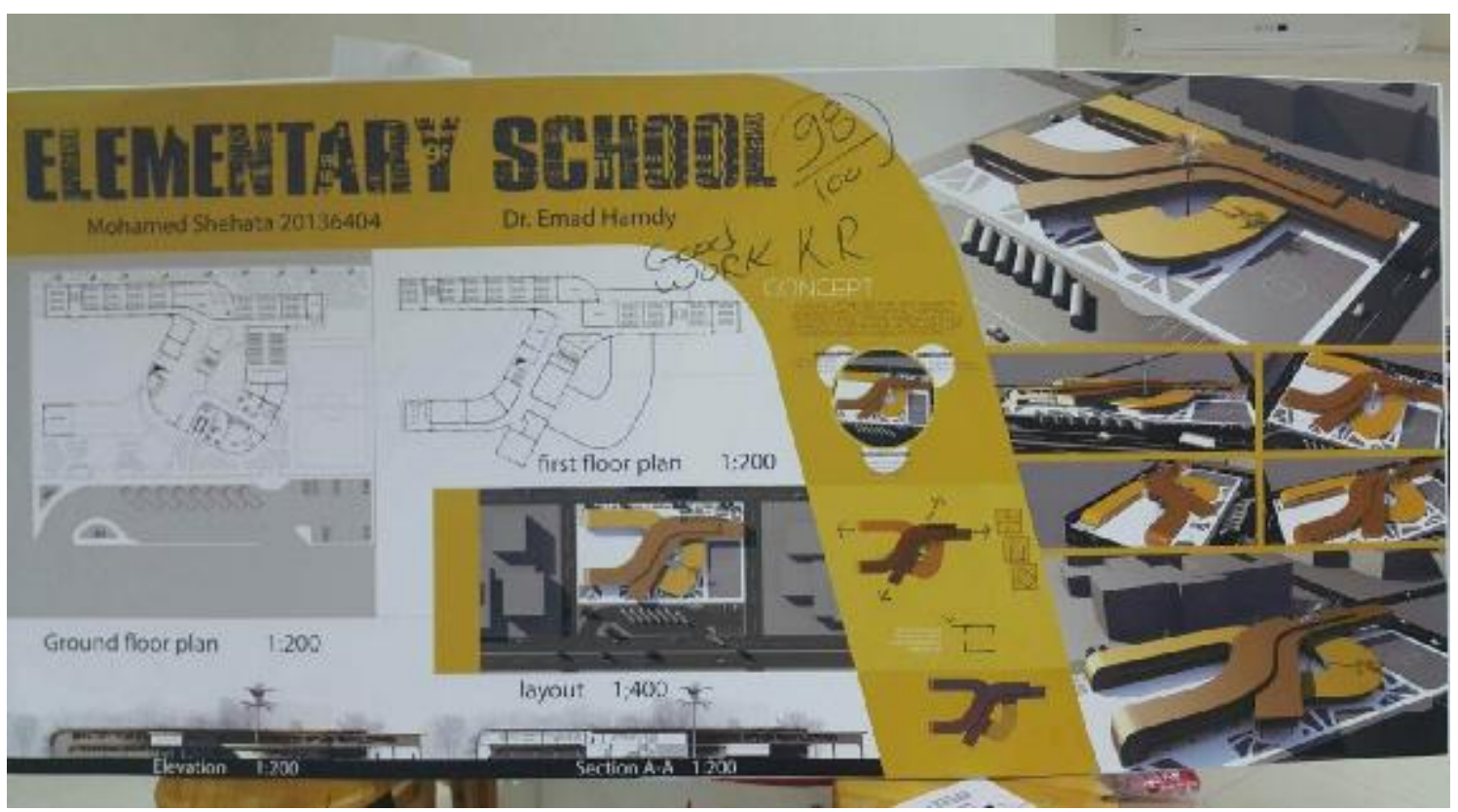

Figure (6) students' project samples after implementing the proposed architecture pedagogy.

\section{Acknowledgment:}

The author would like to thank the CIC administration, as well as all teaching assistants and students who participated in the application of this useful and fruitful experiment. Also would like to thank Ms.Daisy Fedna for the proofreading this study.

\section{REFERENCES:}

1 Demirbaş, O. O., and H. Demirkan. "Focus on architectural design process through learning styles." Design Studies 24.5 (2003): 437-456.

2 Kvan, Thomas, and Yunyan Jia. "Students' learning styles and their correlation with performance in architectural design studio." Design Studies 26.1 (2005): 19-34.

3 Uluoğlu, Belkis. "Design knowledge communicated in studio critiques." Design Studies 21.1 (2000): 33-58.

4 Sagun, Aysu, and Halime Demirkan. "On-line critiques in collaborative design studio." International Journal of Technology and Design Education 19.1 (2009): 79-99.

5Goldschmidt, Gabriela, Hagay Hochman, and Itay Dafni. "The design studio "crit": Teacherstudent communication." Artificial Intelligence for Engineering Design, Analysis and

Manufacturing 24.03 (2010): 285-302.

6 McCullough, Malcolm, William John Mitchell, and Patrick Purcell. "The electronic design studio: architectural knowledge and media in the computer era." (1990).

7 Guney, D. "The Importance of Computer-aided Courses in Architectural Education." Procedia- 
Social and Behavioral Sciences 176 (2015): 757-765.

8Shaffer, David Williamson. Expressive mathematics: Learning by design. Diss. Massachusetts Institute of Technology, 1998.

9 Oxman, Rivka. "Digital architecture as a challenge for design pedagogy: theory, knowledge, models and medium." Design Studies 29.2 (2008): 99-120.

10 Ciravoğlu, Ayșen. "Notes on Architectural Education: An Experimental Approach to Design Studio." Procedia-Social and Behavioral Sciences 152 (2014): 7-12.

11 Ganapathy Iyer, Ashok. "Review of Approaches to Learning adopted by Architecture Students in the Coursework of Architectural Design." Archi-DOCT 3.1 (2015): 21-29.

12Salama, Ashraf M. "A process oriented design pedagogy: KFUPM sophomore studio."

Transactions 2.2 (2005): 16-31.

13Voulgarelis, Hermie, and Jolanda Morkel. "The importance of physically built working models in design teaching of undergraduate architectural students." 2nd International Conference on Design Education, University of New South Wales, Sydney, Australia. 2010.

14 Vyas, Dhaval, Gerrit van der Veer, and Anton Nijholt. "Creative practices in the design studio culture: collaboration and communication." Cognition, Technology \& Work 15.4 (2013): $415-443$.

15 Braae, Ellen, and Anne Tietjen. "Constructing sites on a large scale: towards new design (education) methods." Nordic Journal of Architecture 1 (2011): 64-71.

16HARRISS, HARRIET. "Architecture Live Projects acquiring and applying missing practice-ready skills." (2014).

17Postalci, I. E., and G. Atay. "“Design process of dwelling" as a method in architectural education." sgem 2014 conference on arts, performing arts, architecture \& design. Vol. 1. No. SGEM2014 Conference Proceedings, ISBN 978-619-7105-30-08/ISSN 2367-5659, September 1-9, 2014, Vol. 1, 1175-1182 pp. STEF92 Technology, 2014.

18Uzunoglu, Semra Sema, and Ariz Quriesh. "A Method of Adapting Construction Education in Architectural design Education." Procedia-Social and Behavioral Sciences 51 (2012): 546-552.

19 Salama, Ashraf M. "An exploratory investigation into the impact of international paradigmatic trends on Arab architectural education." GBER-Global Built Environment Review 6.1 (2007): 31-43.

20 Salama, Ashraf MA, and Nicholas Wilkinson, eds. "Design studio pedagogy: Horizons for the future." (2007).

21 Yashaen Luckan. " The Transformation Of Architectural Education Towards Establishing Architecture As Responsive, Relevant And Ethical Social Practice: A Model For Interdisciplinary Collaboration And Social Participation" published in the conference proceedings of the UIA Conference in Durban, South Africa, August 2014.

1. 22 Kuloglu, Nilgün, and Ali O. Asasoglu. "Indirect expression as an approach to improving creativity in design education." Procedia-Social and Behavioral Sciences 9 (2010): 1674-1686.

2. 23Schnabel, M. A., and J. Y. Tsou. "Integration Of Parametric Thinking Within Undergraduate Design Studios.".

3. 24 Bachman, Leonard R., and Christine Bachman. "Designing student learning outcomes in undergraduate architecture education: Frameworks for assessment." Enquiry: A Journal for Architectural Research 6.1 (2009).

4. 25Banta, Trudy W. "A warning on measuring learning outcomes." Inside Higher Education 26 (2007).

5. 26Bachman, Leonard R., and Christine Bachman. "Designing student learning outcomes in undergraduate architecture education: Frameworks for assessment." Enquiry: A Journal for Architectural Research 6.1 (2009). 
PEDAGOGICAL PRAXIS IN ARCHITECTURE DESIGN STUDIO: (CASE STUDY APPLIED ON SOPHOMORE ARCHITECTURE STUDENT)

6. $\quad$ 27Hart, Peter D. "How should colleges assess and improve student learning." Employers' views on the accountability challenge (2008).

Appendix (A)

Evaluation form for proposed pedagogical praxis in architecture design studio

\begin{tabular}{|c|c|c|c|c|c|c|}
\hline \multirow{2}{*}{ Name: } & \multicolumn{6}{|c|}{ ID. } \\
\hline & Item & V. Positive & Positive & medium & Negative & V. Negative \\
\hline 1 & $\begin{array}{l}\text { Built epistemological freedom and open minded } \\
\text { environment in design studio. }\end{array}$ & & & & & \\
\hline 2 & $\begin{array}{l}\text { Counseling In Architecture Decision Making With } \\
\text { The Students. }\end{array}$ & & & & & \\
\hline 3 & $\begin{array}{l}\text { Decrease stresses at the initial phase of the } \\
\text { project }\end{array}$ & & & & & \\
\hline 4 & $\begin{array}{l}\text { Intoductory sessions for the student at the } \\
\text { beginning of the project. }\end{array}$ & & & & & \\
\hline 5 & Work on the student idea. & & & & & \\
\hline 6 & The appraisal of project on nominated criteria & & & & & \\
\hline 7 & $\begin{array}{l}\text { Taking into account individual differences among } \\
\text { students. }\end{array}$ & & & & & \\
\hline 8 & $\begin{array}{l}\text { Illustrate the design process; the timetable for the } \\
\text { project from the first day. }\end{array}$ & & & & & \\
\hline 9 & $\begin{array}{l}\text { Illustrate the design process and project schedule } \\
\text { from day one of the project. }\end{array}$ & & & & & \\
\hline 10 & $\begin{array}{l}\text { Expound the integration in architectural design in } \\
\text { the onset of the project }\end{array}$ & & & & & \\
\hline 11 & $\begin{array}{l}\text { Build mutual trust ambience between the faculty } \\
\text { and students }\end{array}$ & & & & & \\
\hline 12 & $\begin{array}{l}\text { Dividing Students into groups with individual } \\
\text { Instructor to boost the follow-up for each student }\end{array}$ & & & & & \\
\hline 13 & $\begin{array}{l}\text { The faculty stimulus and inducement strategies } \\
\text { were sufficient }\end{array}$ & & & & & \\
\hline 14 & $\begin{array}{l}\text { Assay the prior architecture mindset for the } \\
\text { students, thereafter, planning to reform the } \\
\text { innnnmnriata inano }\end{array}$ & & & & & \\
\hline
\end{tabular}

